Association for Information Systems

AIS Electronic Library (AISeL)

AMCIS 2004 Proceedings

Americas Conference on Information Systems

(AMCIS)

December 2004

\title{
Knowledge as Process, not Data: the role of Process Based Systems in developing organisational knowledge and behaviour.
}

Ivor Perry

De Montfort University

Follow this and additional works at: http://aisel.aisnet.org/amcis2004

\section{Recommended Citation}

Perry, Ivor, "Knowledge as Process, not Data: the role of Process Based Systems in developing organisational knowledge and behaviour." (2004). AMCIS 2004 Proceedings. 45.

http://aisel.aisnet.org/amcis2004/45

This material is brought to you by the Americas Conference on Information Systems (AMCIS) at AIS Electronic Library (AISeL). It has been accepted for inclusion in AMCIS 2004 Proceedings by an authorized administrator of AIS Electronic Library (AISeL). For more information, please contact elibrary@aisnet.org. 


\title{
Knowledge as Process, not Data: the role of Process Based Systems in developing organisational knowledge and behaviour.
}

\author{
Ivor Perry \\ Senior Lecturer \\ De Montfort University \\ United Kingdom \\ iperry@dmu.ac.uk
}

\begin{abstract}
Process-based systems - mostly using emergent technologies like workflow engines, XML standards and so on, are becoming part of organisational life. Yet in automating, or shaping organisational processes, they are making subtle but profound changes in culture, knowledge creation, and knowledge management. This paper will contend that the process of acquiring and managing data is itself a knowledge building process. It will also assert that the process of creating a patient's health record is a dynamic one, which adds to the sum knowledge of the organisation, not just in terms of the accretion of data, but in the understanding and opportunities for reflection which it creates. Finally, the paper will argue that such dynamic knowledge can be used, not only to deliver better healthcare, but to improve the organisational structure and behaviour in order to improve the means by which healthcare is delivered.
\end{abstract}

\section{Keywords}

Process Based Systems, knowledge creation, knowledge management, XML, workflow

\section{INTRODUCTION}

There are already precedents to show that the implementation of information technology systems may have a marked effect positive or negative - on the behaviour of users (Cooper, 1994). This paper considers specifically one category of information systems, which we shall call Processed Based Systems (PBS), and their effect on, and use by users. Their essential characteristic is that they encapsulate and enact processes, rather than data transactions. Examples of PBS include workflow systems, many CRM systems, and many XML-based systems. Many new Content Management Systems (CMS) include PBS technology in order to make use of, as opposed to archive, business content.

Ten years ago, the majority of process based systems were workflow systems, which because of their cost (and the need to obtain a return on that investment) tended to be large systems, often in the financial services industry, which had the financial resources, and the clerical processes amenable to automation. At that time, the technology was exclusively LAN or WAN based, since the underlying structure of the systems (large databases, using multiple transient tables) requires fast data transmission, with a degree of security, in large volume (Doherty and Perry, 1999)

In recent years, the availability and cost of intranet or internet XML based systems for enacting (usually less sophisticated) business processes has enabled health practitioners, with limited budgets, to reengineer or add value to their professional and administrative processes. Specifically, the growing use of Electronic Health Records has had effects beyond the simple availability or speed of transmission of data.

This paper examines the role played by these types of technology in knowledge creation. It is not about (currently accepted forms of) knowledge management systems or decision support systems. Instead, it focuses on processed based systems (PBS) like workflow, or the 'dynamic' electronic records systems currently being implemented throughout the National Health Service of the United Kingdom (NHS). These will be described in more detail later. The paper draws its examples, both in primary and secondary data, from the NHS, which is a well documented and rich source of information.

Over the last 55 years, it has become the second largest consumer of government money, and is now the largest employer in Europe. As a result it is highly visible in political terms; governments and political parties which aspire to government are compelled to demonstrate that they have a 'vision' for the NHS, and that they can demonstrate improvements or reforms. 
Further, the NHS is currently deploying these systems on a hospital-by-hospital basis across the whole country; it is this state of continuing implementation that has both encouraged and is lending an historical perspective to the research.

The National Health Service was founded in 1948 on a number of principles, including

- The provision of a full and complete service 'from cradle to grave', including accident care.

- The service is free at the point of consumption.

- It is available to all.

The government owns the organisation and employs the staff.

Within the NHS, patient care is delivered through a series of Trusts, or quasi-autonomous budget holding units. Trusts are arranged in a three tier hierarchy, with primary Trusts delivering General Practice and community care, Secondary Trusts providing hospital care, and Tertiary Trusts providing training, research, and hospital care. The present government announced in 2002 a programme to invest over $£ 40$ billion in four areas - a new Prescriptions service, a new Patient Bookings service, and a new Electronic Health Record, all of which would be integrated through a new standards-based communications 'backbone' (Department of Health, 2002). One of these, the provision of electronic records, forms the background to the present research.

The effect of workflow systems on organisational culture has already been documented (Perry and Doherty, 2001). However, the systems being deployed in Electronic Patient Records (EPR) within Secondary Trusts were not conceived by their developers or implementers as workflow systems. However, the new EPRs, mostly using XML standards and internet architecture, have been likened to a kind of 'proto-workflow' (Perry, 2003), in which some functions of large (and expensive) database-driven workflow systems appear. For example, they follow a process (building up and amending) a record which is usable by different skills based areas (e.g. clinical departments) for different purposes both simultaneously and at different times. They advance the process, rather than simply calculate transactions. In this way, they fulfil a dynamic, rather than an historic, purpose.

\section{RESEARCH METHODS}

Little has been written in the academic literature about the organisational effects of introducing PBS into organisations, although Ciborra's book, (1996) gave some illuminating perspectives on the effects of using Groupware systems - certainly one of the family of PBS. In response to the lack of information about this type of system, some structured interviews had been carried out in 2002. Managers within five hospital Trusts had been interviewed to gain an understanding of

- the 'business' drivers for implementing XML-based EPR systems,

- the types of implementation process, and

- the response of the organisation to the deployed systems.

This in itself had provoked the interest in the relationship between PBSs and organisational knowledge. Following the grounded theory process used by Orlikowski (1993) amongst others in IS research, it was decided to re-interview two of those managers eight months later. In order to create some triangulation of experience, it was decided that one manager should be an IS professional, and the other should be a clinician, although they each were responsible for an XML based EPR roll-out at the time. Additionally, to take the perspective wider than the two trusts, or indeed Secondary Trusts as a category, another interview was held with a supplier who had provided consultancy and implementation services to both the latter.

This time, managers were specifically asked about the effects on staff of the deployment of the systems. The results of these interviews were then considered in the light of the available literature.

\section{LITERATURE REVIEW}

The NHS has had a history of large change projects, which have frequently encountered considerable resistance. Brown (1998) offers a case study of one of the major changes of the last 20 years - The Resource Management Initiative (RMI) which was announced in 1986 and should have been rolled out to 260 hospitals by 1991 . The significance of this case study for the present paper is that the RMI relied for its success on the development of integrated IT systems that would pass data from Patient Administration systems (which should have incorporated most of the records relating to a hospital stay), Departmental systems (theatre, pathology, radiology, nursing etc) with other and with the Case Mix systems which should calculate cost information. 
However, Brown recorded that none of the hospitals in the region studied had realised all the objectives of the RMI by 1991. Apart from problems of complexity and funding, he had already concluded that RMI was in effect opposed by the hospitals' culture. ".. because most people conceived RMI as essentially a structural and procedural change programme that would do little to further key objectives, especially the improvement of patient care, confidence in and enthusiasm for it were more muted than might otherwise have been the case."

Within the context of organisational knowledge, Tsoukas (1996) focuses on processes of knowing, and in particular the problem of knowledge being distributed (in the sense of being dispersed) throughout the organisation, and also the problem of drawing together specific knowledge for specific purposes. He acknowledges that individuals are subject to the expectations of their job roles in their exercise of knowledge. He also describes the way in which people have a 'dispositional' dimension; in other words, the aggregation of their mental models acquired over time and patterns of socialisation. Finally he argues that there is a further dimension; a social context in which the normative expectations of job roles and the pre-dispositions are specifically brought into play and conditioned. All three dimensions are significant in the creation and exercise of knowledge. His recommendation accordingly is an integrative one; to find ways in which practitioners (those performing the primary tasks of the organisation) can become connected and interrelate the knowledge they each have.

The degree to which PBSs can promote this interconnectivity is unclear from the literature. However, there are indications from writings on PBS- related subjects which are helpful. Orlikowski (1996), in her description of a Groupware - based implementation of a customer support facility, observed that the new, technology-enabled process had the function of collecting not just more data, but more knowledge (for example, agents became able to identify who had previously dealt with a call and on that basis made additional judgements about the quality of advice that had been given). As a result 'the value of the knowledge being generated attracted the attention of others who desired access.' In other words, not only had new knowledge been created from data that had been previously available but was now being processed differently, but that somehow an awareness of that value had been communicated outside the immediate circle of users.

It has been understood for a long time that Process Based Systems have effects on users which go beyond those caused by more conventional transaction based systems like accounting, inventory management, data extraction and so on. Amberg (1996) in a paper which focuses on workflow management systems (WFMS) technology, also makes some telling points: ....."WFMS can help to determine and manage the knowledge vital for an enterprise: What is done (the business processes and workflow) how (the activities and flow of work between activities), by whom (the participating human and automated actors) and with what means (the tools). In particular WFMS focus on how the work is done instead of which work is done. " Here we see a type of PBS being used in a qualitatively different way from conventional technologies. This point is further emphasised by Doherty and Perry (1999) who noted the interrelationship between WFMSs and Business Process reEngineering (BPR) initiatives. In a survey of over thirty major companies in the UK financial services sector, they found that even in those which had not planned the WFMS as a part or co-terminal with a BPR exercise, almost all had, as a result of the new opportunities for changing ways of working, begun some BPR initiatives. Importantly, those initiatives were then being enacted through the medium of the WFMS technology. Interestingly, too, Doherty and Perry in a later paper (2001) identified that other unexpected outcomes had arisen from the implementation of this type of PBS, viz. a change in organisational culture. Prima facie it may be that, in Tsoukas' taxonomy, the new patterns of working were having an effect on workers' 'dispositional' dimension. Another possible interpretation of these effects on knowledge generation may be found in Nonaka's concept of 'ba' - the spaces where knowledge is exchanged and new knowledge created. In this context, one can see that such systems would have implications for 'combination' - explicit-to-explicit information; it is the purpose of these systems to take information, collate it, pass it on, flag anomalies and so on. What is less obvious are the possibilities for 'externalization' - tacit-to-explicit information, or indeed 'internalisation' - explicit-to-tacit.

\section{RESULTS OF THE INTERVIEWS}

In the first round of interviews, organisational knowledge was not specifically addressed. The focus had been to understand the organisational context, and business drivers for, the implementation of XML-based EPR systems. However, a number of comments were being made which later resonated with aspects of the literature as described above. Firstly, although only one interviewee had specifically used the system to re-engineer organisational culture, the others had begun to notice a change in the culture of the staff who used the system. They reported that clinical departmental barriers were being breached, and that clinicians showed strong support for the systems. Additionally, they had consulted widely, and had been deliberately inclusive in their steering committees, or advisers. Out of ten possible categories of staff who might have been involved in the implementation, all Trusts had used nine categories. In terms, therefore of knowledge of the existence of the system, there was a very wide dissemination at the outset. Further, all Trusts had secured senior management sponsorship throughout the process of selection and implementation. While this is now a commonplace of project management textbooks (Yeates and 
Cadle 1996), it may be significant in the context of hospital Trusts. On the subject of culture, interviewees had broadly agreed that most areas of hospitals had a power-based culture, where power mostly lay in the hands of senior clinicians. There was a sense in which both the involvement of a wide range of stakeholders and the senior managers were attempts to get the holders of power 'onside'.

Eight months later, two managers were interviewed again. Both reported that the systems were not only being intensively used, but that they were under pressure from most departments either to enrich the EPR system (if it was already installed) or to install it. Manager A, a clinician, whose EPR system had first been installed in the Accident and Emergency and Medical Assessment units, said that it was now regarded by almost all staff not just as a record of what patients were present, but as both an aid to diagnostics and as a logistics tool. Clinicians could see at a glance the sum of knowledge about the patient, or where additional knowledge could be found (e.g. details of the G.P.), and they could also see exactly how many patients were waiting treatment. They were then using this in the allocation of beds, and in negotiations with the administrative departments for the provision of resources. He believed the records system had proved that it not only managed the historical data, but significantly helped to manage the processes of understanding patient needs and even of managing patient 'throughput' (the researcher's terminology). He described the way in which common assumptions (that extra beds could not be found, that the administrative department was intentionally unhelpful) were being overcome when a fuller picture, compiled by the system, was presented. In Nonaka's (1991) terms, this appears very close to externalization; it takes existing, tacit assumptions and brings them together with explicit information to create new knowledge. In this case, the new knowledge was that the administrative department were not being deliberately unhelpful, since when the true state of affairs could be demonstrated, they worked hard to free up resources for the nursing staff. The records had become a dynamic force in enabling a higher standard of patient care. The challenge, he felt, now lay in extending the system away from dynamic records to organising and predicting the workflow of the hospital.

Manager B, an IS professional, was less prepared to force the pace of change, and had adopted a 'customer led' approach. His steering committee, comprised almost entirely of clinician and nursing staff, prioritised the functionality and the departments for future stages. He stated that while the medical nature of the steering committee had been his design, the actual individuals who comprised it were self-selecting. This, he believed, was consistent with the culture of the hospital, and indeed he would have expected such to be the case in any hospital. It left him with a group of users who were on the whole enthusiastic (though they could also be highly critical) which brought him the advantages of disseminating positive information about the system, and inputting accurate and constructive ideas about the processes themselves. On the other hand, it left him with one department that had no representation at all. Self-selection meant that that department, with a consultant who was deeply sceptical, was not represented. Its junior staff consistently refused to participate in the steering committee, pleading pressure of work. As a result, the take up (in terms of workstations) and the use of the system in that department had been smaller, and the percentage of problems higher, than in others. It also, he believed, contributed to that department's isolation. It had always been seen as separate, due apparently to the personality of the consultant, but that its separateness was now thrown into high relief because other departments were collaborating much more. Manager B ascribed this increase in collaboration mainly to the EPR system. It had, he said, significantly eased the flow of information between departments, and, by removing 'friction points' had encouraged more participation and sharing of information.

The interview with the supplier was designed to obtain a broader perspective by asking the interviewee to draw on his experience of the fifteen implementations with which he had been involved. He agreed that in all fifteen, there had been the same pattern of wide consultation and appeal to the 'holders of power', which he considered to be typical of NHS hospital culture. He also confirmed the apparent pattern established by the two NHS managers; that the systems were being taken up with enthusiasm by user departments, and were being requested by others. He had encountered considerable initial suspicion, especially among clinicians, that their preferred ways of working would be disrupted. However, the use of XML stylesheets and tagging meant that those who wished to work in a certain way were able to continue, as the technology enabled separation of content and form. In other words, those departments that had always had their records laid out in certain ways, and had always had their own order in which they searched or referred to documents, were able to keep them. He acknowledged that this was contrary to the 'received wisdom' in the PBS industry, namely that the automation of a poorly designed process resulted in a fast, poorly designed process, with little gain. However, he considered that to be a worthwhile trade-off in terms of avoiding cultural resistance, at least within the same Trust, where departments may vary in their practices, but there had always been significant nodes, or meeting-points of information.

\section{CONCLUSIONS}

The findings from the literature and the primary research, when viewed in combination, produce a number of perspectives on the nature of knowledge, organisational culture, and Process Based systems. If we follow Ashby's (1955) concept of requisite variety, it follows that the amount of information created in the environment will be matched by the creation of information 
channels. In the case of PBSs, we may argue that the requisite variety becomes an upward spiral of knowledge generation matched by increasing diversity and flexibility of the system. This diversity and flexibility, it is argued, is made possible by the nature of the technology, which is able to emulate and encapsulate processes.

Stewart (1997) argues that knowledge is not like any other economic resource - for example knowledge can be sold more than once; the amount of effort used to create it is not necessarily related to the amount or value of the knowledge; finally it is abundant, yet the conventional laws of economics suggest that value derives from scarcity, not abundance. Some of these precepts have considerable attractions for busy and under-funded hospitals. If knowledge can be accreted rather than sought, then less time, and more importantly, less practitioner time, is consumed in the process of knowledge creation. More consideration needs to be given to this concept of accumulating knowledge by process. In the EPR systems studied, the accretion of knowledge is partly intentional (each department or clinician adding to the record to provide helpful information for the next practitioner) and partly unintentional (the ability to search across records without predefined search paths, the ability to 'see' an holistic view of a patient's situation). Moreover, for busy professionals, the input or effort required to obtain information is reduced. Whether that effort results in more time spent on other activities or less stress, is not yet clear, and may offer further fruitful insights in subsequent research.

Clearly, the influence of organisational culture on both process and then on knowledge creation is a significant one. Endorsement in an essentially power - driven culture by the holders of that power (in this case the clinicians) results not only in the system's success, but also in the development of both the process and its knowledge-enhancing properties. This seems to line up with both Tsoukas' (1996) and Doherty and Perry's (2001) observations. The important question of course is, why did clinicians endorse this change? For the answer, we should return to Brown's (1998) study of the problems in the take up of the Resource Management Initiative in the late 1980s. It, and significantly the technology that underpinned it, was expensive, complex, and not perceived as directly relating to the organisational objectives (i.e. patient care). Largely, the use of XML technology has removed the cost issue; the ability of the same technology to enact business processes has allowed users to feel both in control and empowered to make changes in areas they perceive as significant to their job roles.

Thus, the XML- based PBSs that are now being adopted, are arguably significantly affecting organisational knowledge. Taking Tsoukas' (1996) proposition that the use of knowledge is conditioned by the normative expectation of people's organisational function, we see that these systems, by enabling that organisational function to run more smoothly and with more intelligible information, change the normative expectations of users. Secondly, to the extent that these systems then permit cross-functional interaction, we see the possibility of changed mental models, of perception of others, and of what is possible. Finally, these systems permit the coming-together, the specific social context, in which the normative expectation and the 'dispositional' dimension operate. Further, they do so in the context of a structured process that is perceived to be under the control of the user community.

Further, we can look at the exercise of these PBS systems in the light of Nonaka's (1990) ideas on information redundancy, and the concept of 'overlapping ideas' "....overlapping within and across team members' functions encourages meaning creation. Once semantic information is created, it naturally seeks similar meaning in an effort to self-organize". We should not be surprised then that additional 'value' is perceived in the information provided by the electronic records, in terms of spinning off towards richer diagnostics or better bed allocation.

In the context of the NHS, where change has been frequently associated with large, government, politically motivated change programmes (Fairey, 2002), the changes observed here are small, but significant. No attempt has been made overtly to change business processes; both Manager A and Manager B said that the initial objective had been to make existing processes more efficient. However, we see signs both that new knowledge has been created and that new processes are either happening by default or are being discussed.

A summary perspective on PBS is suggested by Bhatt (2000) "The challenge for organizations is to create an environment that demands and allows generation and processing of information continually". The growing body of evidence is that PBSs are doing just that.

\section{FURTHER RESEARCH}

Many questions from this short study remain unresolved. Will users come to be dependent on these EPR systems to the detriment of objective thinking? The possibility needs at some point to be confronted, as their ease of use encourages more reliance on them. With the old, paper-driven systems, there were at least many opportunities at which the system halted, waiting for reports to catch up. Did these hiatus points contribute to good clinical reflection, or were they just, as has been believed by the present practitioners, 'friction points'? 
Will the processes, now so easy to enact, condition thinking and prevent users from generating new ideas? The indications at the moment are that users are using the systems to generate additional, and more functional processes, yielding richer seams of knowledge. However, will the users soon become satiated and no longer use the system to provoke new ideas?

Clearly, there is much still to be done in understanding the role and potential of Process Based Systems over time; further, their relationship to the matrix of business process-knowledge creation-organisational culture has not been explored at all. However, it seems clear that, in addition to influences on organisational processes and culture, they are making a clear if unintended contribution to organisational knowledge as well.

\section{REFERENCES}

1. Stewart, T. (1997) Intellectual Capital: The New Wealth of Organizations, Doubleday, Toronto

2. Brown, A. (1998) Organisational Culture ( $2^{\text {nd }}$ edition), Prentice Hall, Harlow, England

3. Perry, I F. Making sense of the organisation's knowledge: does systematisation of the knowledge base have a positive or negative effect on organizational culture?" (Proceedings of) HICSS '36 ( $36^{\text {th }}$ Hawai'i International Conference on System Sciences) January 2003

4. Cooper, R.B. (1994) "The Inertial Impact of culture on IT Implementation", Information and Management, 27, 17-31.

5. Doherty N.F. and Perry I.F., "The Cultural Impact of Workflow Management Systems in the Financial Services Sector", The Service Industries Journal, Vol.21, No.4 October 2001, pp 147-166

6. Department of Health. Delivering IT in the NHS - A summary of the national programme for IT. www.doh.gov.uk/ipu/whatnew/deliveringit/deliveringit.htm accessed August 2002

7. Ciborra, (ed) (1996) Groupware and Teamwork: Invisible Aid or Unnecessary Hindrance? Wiley, Chichester, England

8. Orlikowski, W. CASE Tools as Organizational Change: Investigating Incremental and Radical Changes in Systems Development: Management Information Systems Quarterly Vol 17, No. 3, September, 1993

9. Orlikowski, W. (1996) Evolving with Notes: Organizational Change around Groupware Technology. In Ciborra, (ed) (1996) Groupware and Teamwork: Invisible Aid or Unnecessary Hindrance? Wiley, Chichester, England

10. Tsoukas, H. (1996) The Firm as a Distributed Knowledge System: A Constructionist Approach, Strategic Management Journal, 17, Winter Special Issue, 11-25

11. Ashby, W. (1955) An Introduction to Cybernetics, Chapman and Hall, London

12. Amberg, M. (1996) Enhancing the Competitiveness of Enterprises by Applying Advanced Workflow Management Systems. European Conference on Management in Face of Knowledge Driven Competition, Porto, Portugal, September

13. Doherty N.F. and Perry I.F., "The Uptake and Application of Workflow Management Systems in the UK Financial Services Sector", Journal of Information Technology, 14(2), 1999, pp 149-160, ISSN 0268-3962

14. Yeates, D. and Cadle, J. Project Management For Information Systems ( $2^{\text {nd }}$ Edition) Pitman Publishing, 1996

15. Nonaka, I. (1990) Redundant, Overlapping Organization: A Japanese Approach to Managing the Innovation Process, California Management Review, Vol 32, No 3

16. Nonaka, I. (1991) The knowledge creating company. Harvard Business Review, Nov-Dec 1991, 96 - 104

17. Fairey, M. Culture Change Ahead. British Journal of Healthcare Computing and Information Management, Vol 19, No 8, October 2002

18. Bhatt, G.D. Organizing Knowledge in the knowledge development cycle, Journal of Knowledge Management, Vol 4, Issue 1,2000 